\title{
Systolic time ratio measured by impedance cardiography accurately screens left ventricular diastolic dysfunction in patients with arterial hypertension
}

\author{
Rodrigo Nazário Leão ${ }^{1,2^{*}}$ (D) Pedro Marques Silva ${ }^{2,3}$, Luísa Branco ${ }^{4}$, Helena Fonseca ${ }^{3}$, Bruno Bento ${ }^{5}$, Marta Alves ${ }^{6}$,
} Daniel Virella ${ }^{6}$ and Roberto Palma Reis ${ }^{2,5}$

\begin{abstract}
Background: The use of impedance cardiography (ICG) may play a role in the assessment of cardiac effects of hypertension (HT), especially its hemodynamic features. Hypertensive heart disease involves structural changes and alterations in left ventricular geometry that end up causing systolic and/or diastolic dysfunction. The IMPEDDANS study aims to assess the usefulness of ICG for the screening of left ventricular diastolic dysfunction (LVDD) in patients with HT.

Methods: Patients with HT were assessed by echocardiography and ICG. Receiver-operating characteristic curve and the area under the curve were used to assess the discriminative ability of the parameters obtained by ICG to identify LVDD, as diagnosed by echocardiography.

Results: ICG derived pre-ejection period (PEP), left ventricle ejection time (LVET), systolic time ratio (STR) and D wave were associated $(p<0.001$ ) with LVDD diagnosis, with good discriminative ability: PEP (AUC 0.81 ; 95\% Cl 0.740.89), LVET (AUC 0.82; 95\% Cl 0.75-0.88), STR (AUC 0.97; 95\% Cl 0.94-1.00) and presence of D wave (AUC $=0.87 ; 95 \%$ Cl $0.82-0.93$ ). STR $\geq 0.30$ outperformed the other parameters (sensitivity of $98.0 \%$, specificity of $90.2 \%$, positive predictive value of $95.2 \%$, and negative predictive value of $96.1 \%$ ).

Conclusion: The ICG derived value of STR allows the accurate screening of LVDD in patients with HT. It might as well be used for follow up assessment.
\end{abstract}

Trial registration: The study protocol was retrospectively registered as IMPEDDANS on ClinicalTrials.gov (ID: NCT03209141) on July 6, 2017.

Keywords: Arterial hypertension, Diastolic dysfunction, Impedance Cardiography, Systolic time ratio, Screening

\section{Background}

Arterial hypertension (HT) causes high morbidity and mortality [1]. The progression of hypertensive heart disease involves myocardial fibrosis and changes in left ventricular geometry that precedes functional changes [2]. Diastolic dysfunction is part of this continuum, and despite the growing recognition of its importance, it is

\footnotetext{
* Correspondence: rodrigoromaoleao@gmail.com

${ }^{1}$ Unidade Funcional Medicina 1.2, Hospital de São José, Centro Hospitalar Lisboa Central-EPE, Rua José António Serrano, 1150-199 Lisboa, Portugal ${ }^{2}$ NOVA Medical School, Universidade NOVA de Lisboa, Lisboa, Portugal

Full list of author information is available at the end of the article
}

generally undervalued because of the difficulty in its diagnosis and the absence of effective therapies [3]. Currently, the asymptomatic cardiac damage repercussion of $\mathrm{HT}$ is mainly evaluated by electrocardiography and by echocardiography [4]. Cardiac magnetic resonance imaging (MRI) is an alternative diagnostic examination but should only be considered for assessment of left ventricle (LV) size and mass when echocardiography is not feasible (or, in less frequent situations, when imaging of delayed enhancement could have therapeutic implications). Impedance cardiography (ICG) is a non-invasive, non-operator dependent, low-cost complementary diagnostic tool that easily allows 
characterizing a hypertensive patient's hemodynamic phenotypic profile and optimizing the antihypertensive therapy $[5,6]$. It analyses and registers hemodynamic changes through the measurement of electrical resistance changes in the thorax and translating them graphically as impedance and electrocardiogram waveforms $[5,7,8]$. This technique has evolved in recent years, making it an attractive and economical alternative approach. However, it is recognized that well-designed clinical trials are lacking in well-defined populations, in order to justify its widespread use in clinical practice [9-12]. Some other more specific procedures are reserved only for diagnosis of myocardial ischaemia in hypertensive patients with LV hypertrophy [4]. Therefore it is important to have alternative tests for the initial assessment of diastolic function in hypertensive patients.

In diastolic dysfunction, there is a relative shift in LV filling to the final part of the diastole with a greater dependence on atrial contraction. These changes can be detected by Doppler echocardiography and by ICG [2].

The phase of rapid passive ventricular filling at the onset of diastole produces the $\mathrm{E}$ wave and the atrial contraction produces the A wave. The $\mathrm{E}$ and the $\mathrm{A}$ waves on the Doppler sonography correspond to the $\mathrm{O}$ and A waves in ICG, respectively $[13,14]$. Normally, the $\mathrm{E}$ wave in Doppler is higher than the A wave, whereas in diastolic dysfunction, the $\mathrm{E}$ wave is prolonged and becomes smaller than the $\mathrm{A}$ wave. ICG can detect diastolic dysfunction by revealing a delayed $\mathrm{O}$ wave (called a $\mathrm{D}$ wave) when contractility is normal, [14] whereas diastolic dysfunction produces a significant increase in the amplitude and duration of $\mathrm{A}$ wave
(Fig. 1) [5]. A D wave with an amplitude above the $d Z / d t$ baseline greater than one third of the amplitude of the corresponding $\mathrm{E}$ wave is considered abnormal [15].

The pre-ejection period (PEP), corresponding to the interval between the depolarization onset (Q-wave) and aortic valve opening that includes the excitationcontraction coupling and isovolumetric contraction of the LV, decreases with increasing LV pressure at the end of diastole, the main physiological consequence of diastolic dysfunction [16-18]. On the other hand, the left ventricular ejection time (LVET), measured as the interval between the opening of the aortic valve and its closure, increases in patients with diastolic dysfunction. It has been reported that a marked increase in LVET occurs in patients with isolated diastolic dysfunction and that this increase correlates with the severity of diastolic dysfunction [19]. Thus, in diastolic dysfunction, the systolic time ratio (STR) is expected to decrease (STR = PEP / LVET).

The thoracic fluid content (TFC) reflects the total volume of fluid (intravascular and extravascular) within the thoracic cavity, being inversely related to patient transthoracic electrical bioimpedance. It is therefore a reliable index of fluid overload in ambulatory patients. This parameter increases with the evolution of diastolic dysfunction being a sign of severity and has recently been proposed for monitoring diastolic heart failure patients [20, 21].

The purpose of IMPEDDANS study is to assess the usefulness of ICG in the screening of LV diastolic dysfunction (LVDD) in patients with HT.

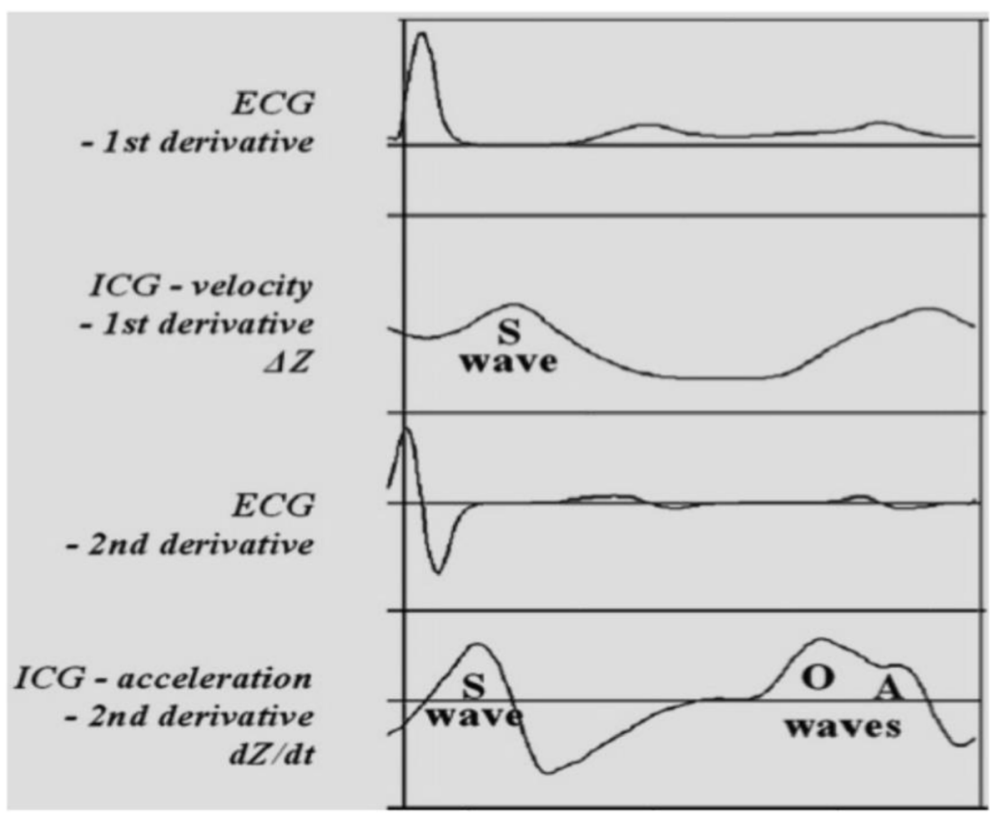

Fig. 1 ICG waves in diastolic dysfunction (adapted from Bour et al. [5]) 


\section{Methods}

This is a validation study of a diagnostic method (ICG) used for a new purpose (diagnosis of LVDD) comparing it with the clinical standard (echocardiography), the method currently used for this effect in usual clinical practice.

Patients of either gender, aged 18-75 years, diagnosed with grade 2 or $3 \mathrm{HT}$ (systolic blood pressure $[\mathrm{BP}] \geq$ $160 \mathrm{mmHg}$ and/or diastolic $\mathrm{BP} \geq 100 \mathrm{mmHg}$ ) and/or with resistant hypertension (according the definition of ESH/ESC guidelines), [4] followed up in ambulatory clinic of an Internal Medicine Department of a tertiary referral hospital were eligible for recruitment.

Patients were excluded in the presence of: pregnancy, height less than $120 \mathrm{~cm}$ or more than $230 \mathrm{~cm}$, weight less than $30 \mathrm{~kg}$ or greater than $155 \mathrm{~kg}$, heart failure II-IV NYHA, [22] heart rate (HR) less than $50 \mathrm{bpm}$ or greater than $110 \mathrm{bpm}$, atrial fibrillation or flutter, more than three premature ventricular contractions per hour, complete left bundle branch or atrioventricular block, pacemaker, severe valvulopathy, constrictive pericarditis, hypertrophic and restrictive cardiomyopathy, ischaemic heart disease and/or segmental kinetics anomalies assessed by echocardiography, left ejection fraction $<50 \%$, or poor echocardiographic window.

Recruitment began in January 2015 and was finished in July 2017.

Sample size was estimated to test a hypothesized positive predictive value of $70 \pm 5 \%$ of the ICG parameters with $95 \%$ confidence. Since the prevalence of LVDD in patients with HT is estimated, in most studies, [2, 23, 24 ] to be approximately $50 \%$, to reach an effective sample of 77 patients with LVDD, the sample to be recruited was doubled to 154 hypertensive patients.

Considering that it would not be ethically acceptable to perform right heart catheterization of patients with grade 2 or $3 \mathrm{HT}$, we chose to design a concordance study between ICG and echocardiography, which is the clinical standard for the diagnosis of LVDD and characterization of hypertensive cardiomyopathy.

Participants were invited to be systematically assessed by ICG and echocardiography, within a maximum interval of 8 days. To ensure that both tests were performed under similar conditions, evaluations matching variations greater than $10 \%$ in $\mathrm{BP}$ or variations more than $5 \%$ in $\mathrm{HR}$ were not considered. These patients were asked to repeat at least one of the exams. If the variations persisted, they were excluded.

Demographic and clinical baseline data were collected from the patients' medical records. Outpatient HT clinic protocol requires clinical evaluation, blood chemistry tests, electrocardiogram (EKG) and, eventually, 24 h ambulatory blood pressure monitoring (AMBP). Data regarding the comorbidities and medication were collected. Body mass index was calculated as weight $(\mathrm{kg})$ divided by height $(\mathrm{m})$ squared.
ICG was carried out by an experienced cardiopneumology technician with Niccomo - Non-Invasive Continuous Cardiac Output Monitor (Medis, GmbH, Ilmenau, Germany) according the approved department protocol. According to this, patients had to present with $6 \mathrm{~h}$ of fasting but took their usual antihypertensive drugs. It was carried out in supine position during $20 \mathrm{~min}$ (continuous recording) and $70^{\circ}$ orthostatism with the help of the tilting table (10 min in continuous recording). The test was interrupted if there was syncope or pre-syncope; dizziness, nausea and malaise associated with poorly tolerated hypotension and/or bradycardia; pain/precordial discomfort; EKG ST segment changes; systolic BP > $210 \mathrm{mmHg}$. Table 1 presents the evaluated parameters.

Transthoracic echocardiography was performed in Vivid E9 and S5 devices (GE Healthcare, Chicago, Illinois, USA), always by the same three experienced cardiologists. To ensure uniformity of evaluation and correct evaluation, all exams were reviewed by one of the other cardiologists. In order to diagnose and classify diastolic dysfunction, the left atrium volume index, the velocities E, A, septal e', lateral e', deceleration time (DT), isovolumetric relaxation time (IRVT), atrial reverse velocity (Ar) and E/A ratio variation with Valsalva manoeuvre were recorded (whenever the patient cooperated and if the images obtained had the necessary quality for analysis) as recommended by 2009 guidelines. We considered that patients had LVDD when present septal $\mathrm{e}^{\prime}<8$, lateral $\mathrm{e}^{\prime}<10$ and left atrial volume equal or greater than $34 \mathrm{~mL} / \mathrm{m}^{2}$ (Fig. 2) [25].

The estimated efficacy and effectivity measures are the positive predictive value (PPV), negative predictive value (NPV), sensitivity and specificity of the presence of the $\mathrm{D}$ wave and the values of PEP, LVET, STR, and TFC obtained by ICG to detect LVDD.

Categorical variables were described with frequencies and percentages. After evaluating the normal distributions of the continuous variables by the KolmogorovSmirnov test and histograms analysis, the variables that presented normal distribution were described with mean and standard deviation, and the variables without normal distribution were described with median and interquartile range (25th percentile, $\mathrm{P}_{25}-75$ th percentile, $\mathrm{P}_{75}$ ) or amplitude (minimum - maximum).

To compare the ICG parameters between patients with and without LVDD, Mann-Whitney test was used. Cut-off points were determined for ICG parameters (PEP, LVET and STR) as predictors of occurrence of LVDD. Using the receiver-operating characteristic (ROC) curve cut-off points were determined regarding the diagnosis of LVDD capacity for screening purposes, thus high sensitivity was considered (>90\%). The area under the curve (AUC) was estimated and 95\% confidence intervals calculated using the binomial exact 
Table 1 Parameters assessed in impedance cardiography

\begin{tabular}{|c|c|c|}
\hline Parameter & Definition & Formula \\
\hline Heart rate & Number of heart beats per minute (bpm) & $\begin{array}{l}\text { RR interval measurement on the ECG and } \\
\text { extrapolation for bpm }\end{array}$ \\
\hline Mean blood pressure (MAP) & Average pressure exerted by the blood on the arterial walls & $\begin{array}{l}\text { Automatic (oscillometric method) = MAP is } \\
\text { measured directly and SBP and DBP are } \\
\text { derived }\end{array}$ \\
\hline Cardiac output (CO) & Amount of blood ejected from the left ventricle / minute & $\mathrm{CO}=$ Stroke volume $\times$ Heart rate \\
\hline Cardiac index $(\mathrm{Cl})$ & Standard CO for the body surface area (BSA) & $\mathrm{Cl}=\mathrm{CO} / \mathrm{BSA}$ \\
\hline Stroke volume (SV) & $\begin{array}{l}\text { Amount of blood ejected from the left ventricle / heart } \\
\text { beat }\end{array}$ & $\begin{array}{l}\text { SV }=\text { VEPT } \times \text { LVET } \times \text { VI } \\
(Z \text { MARC Algorithm) }\end{array}$ \\
\hline Stroke volume index (SVI) & Standard SV for the BSA & $\mathrm{SVI}=\mathrm{SV} / \mathrm{BSA}$ \\
\hline Vascular systemic resistance (VSR) & Resistance to circulating blood in the arterial system & $\mathrm{VSR}=80 \times((\mathrm{MAP}-\mathrm{CVP}) / \mathrm{CO})$ \\
\hline Vascular systemic resistance index (VSRI) & $\begin{array}{l}\text { Standard resistance to circulating blood in the arterial } \\
\text { system for the BSA }\end{array}$ & $\mathrm{VSRI}=80 \times((\mathrm{MAP}-\mathrm{CVP}) / \mathrm{Cl})$ \\
\hline Acceleration index (Al) & $\begin{array}{l}\text { Initial acceleration of blood in the aorta that occurs within } \\
\text { the first 10-20 milliseconds after opening of the aortic } \\
\text { valve }\end{array}$ & $\mathrm{Al}=\left(\mathrm{d}^{2} \mathrm{Z} / \mathrm{dt}_{\text {Max }}^{2}\right) / T F \mathrm{I}$ \\
\hline Velocity index (VI) & Aorta blood velocity peak & $\mathrm{VI}=\left(\mathrm{dZ} / \mathrm{dt}_{\mathrm{Max}}\right) / \mathrm{TFI}$ \\
\hline Thoracic fluid (TF) & $\begin{array}{l}\text { Electrical conductivity of the thoracic cavity (determined by } \\
\text { intravascular, interalveolar and interstitial fluids) }\end{array}$ & $\mathrm{TF}=1 / \mathrm{TFI}$ \\
\hline Left heart work (LHW) & $\begin{array}{l}\text { Indicator of the amount of work the left ventricle exerts to } \\
\text { pump blood every minute }\end{array}$ & $L H W=(M A P-P A O P) \times C O$ \\
\hline Left heart work index (LHWI) & Standard LHW for the BSA & $L H W=(M A P-P A O P) \times C l$ \\
\hline Systolic time ratio (STR) & Ratio of electrical and mechanical systole & $\mathrm{STR}=\mathrm{PEP} / \mathrm{LVET}$ \\
\hline Pre-ejection period (PEP) & $\begin{array}{l}\text { Time interval from the beginning of the electrical } \\
\text { stimulation of the ventricles to the beginning of the } \\
\text { opening of the aortic valve (electric systole) }\end{array}$ & $\begin{array}{l}\text { Time interval between the start of wave } \mathrm{Q} \text { on } \\
\text { the ECG and point } \mathrm{B} \text { on wave } \mathrm{dZ} / \mathrm{dt} \\
\text { (opening of the aortic valve) }\end{array}$ \\
\hline Left ventricular ejection time (LVET) & $\begin{array}{l}\text { Time interval from opening to closing of the aortic valve } \\
\text { (mechanical systole) }\end{array}$ & $\begin{array}{l}\text { Time interval from point } B \text { to point } X \text { on } \\
\text { wave } d Z / d t\end{array}$ \\
\hline
\end{tabular}

CVP Central venous pressure (pressure in the thoracic and right atrial vein $-6 \mathrm{mmHg}$ is considered by default), $d Z$ / $d t_{\text {Max }}$ Maximum of the first derivative of $\Delta Z$, $d^{2} Z / d t_{\text {Max }}^{2}$ Maximum of the second derivative of $\triangle Z, P A O P$ Pulmonary artery occlusion pressure (considered by default as $10 \mathrm{mmHg}$ ), TFI Thoracic fluid index (baseline thoracic impedance, $Z_{0}$ ), VEPT Volume of electrically participating tissue (conductive volume for chest size affected by weight, height and sex)

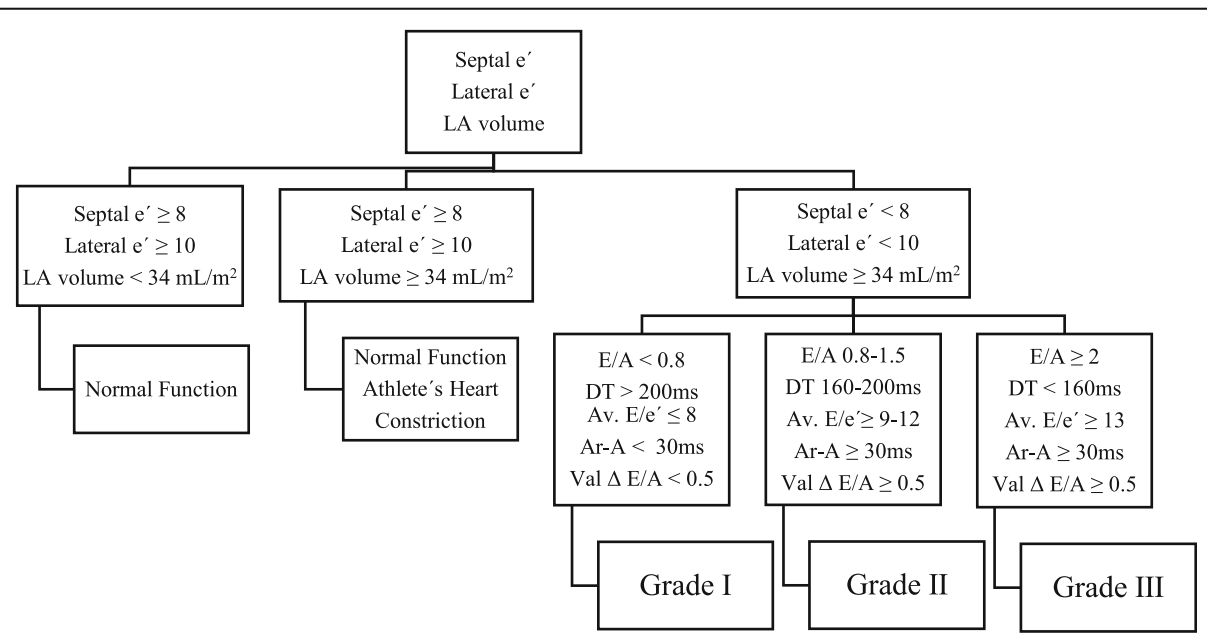

Fig. 2 Practical approach to grade diastolic dysfunction (adapted from Nagueh et al. [25]) 
confidence interval method [26]. Dichotomized ICG parameters by the obtained cut-off points, were used to estimate the test performance measures (sensitivity, specificity, positive and negative predictive values as well as false positive and negative rates). The level of significance $\alpha=0.05$ was considered. Data were analysed with SPSS 22.0 (SPSS for Windows, Rel. 22.0.1. 2013. SPSS Inc., Chicago, Il, EUA) and MedCalc Statistical Software version 16.4.3 (MedCalc Software bvba, Ostend, Belgium; https://www.medcalc.org; 2016).

The study protocol was approved by the hospital's Ethics Committee (approval number 166/2014). Informed consent was obtained from each patient.

The study protocol is registered as IMPEDDANS on ClinicalTrials.gov (ID: NCT03209141).

\section{Results}

IMPEDDANS study recruited 167 patients. Ten patients were excluded: three had syncope during ICG, three gave up and did not perform the tests, three had a significant dysrhythmia and one was diagnosed with atrial septal defect. From the 157 hypertensive patients included, 102 (65\%) had LVDD (diagnosed by echocardiogram). Table 2 shows the main demographic, clinical and hemodynamic characteristics of the patients.

The patients with LVDD diagnosis had significantly lower PEP and STR and higher LVET and TFC than the patients without LVDD (Table 3 and Fig. 3). The D wave was more frequently identified among patients with LVDD (Table 3) and its presence was also associated with LVDD diagnosis.

The diagnostic performance was estimated for those ICG parameters significantly associated with the diagnosis of LVDD. The AUC estimated for PEP was 0.81 (95\% CI 0.74-0.87; $p<0.001$ ), for LVET the AUC was 0.82 (95\% CI $0.75-0.87 ; p<0.001$ ), the AUC was 0.97 (95\% CI $0.93-0.99 ; p<0.001)$ for STR and for the presence D wave the AUC was 0.88 (95\% CI $0.82-$ $0.93 ; p<0.001$ ) (Fig. 4). From the analysis of the ROC curves, were defined the following cut-off points for

Table 2 Main characteristics of the effective sample $(n=157)$

\begin{tabular}{|c|c|c|c|}
\hline & $\begin{array}{l}\text { All patients } \\
(n=157)\end{array}$ & $\begin{array}{l}\text { Without LVDD } \\
(n=55)\end{array}$ & $\begin{array}{l}\text { With LVDD } \\
(n=102)\end{array}$ \\
\hline Males, n (\%) & $88(56.1)$ & $28(50.9)$ & $60(58.8)$ \\
\hline Age, mean (SD) & $63(10)$ & $58(11)$ & $65(9)$ \\
\hline Caucasian, n (\%) & $142(90.4)$ & $48(87.3)$ & $94(92.1)$ \\
\hline HT duration (months), mean (SD) & $120(104)$ & $47(53)$ & $160(104)$ \\
\hline Resistant HT, n (\%) & $117(74.5)$ & $41(74.5)$ & $76(74.5)$ \\
\hline Obesity, n (\%) & $82(52.2)$ & $31(56.4)$ & $51(50.0)$ \\
\hline Diabetes Mellitus, n (\%) & $81(51.6)$ & $28(52.8)$ & $53(51.9)$ \\
\hline Dyslipidaemia, n (\%) & $133(84.7)$ & $47(85.5)$ & $86(84.3)$ \\
\hline CKD, n (\%) & $49(31.2)$ & $12(21.8)$ & $37(36.3)$ \\
\hline Stroke, n (\%) & $36(22.9)$ & $13(23.6)$ & $23(22.5)$ \\
\hline COPD, n (\%) & $20(12.7)$ & $5(9.1)$ & $15(14.7)$ \\
\hline OSA, n (\%) & $31(19.7)$ & $8(14.5)$ & $23(22.5)$ \\
\hline Smoker, n (\%) & $34(21.7)$ & $6(10.9)$ & $28(27.5)$ \\
\hline Alcoholic, n (\%) & $16(10.8)$ & $6(10.9)$ & $10(98.0)$ \\
\hline $\mathrm{N}^{\circ}$ of AHT drugs, median (min-max) & $4(1-7)$ & $4(1-7)$ & $4(1-6)$ \\
\hline $\mathrm{SBP}(\mathrm{mmHg})$, median $\left(\mathrm{P}_{25}-\mathrm{P}_{75}\right)$ & $131(122-142)$ & $124(118-135)$ & $133(126-144)$ \\
\hline DBP $(\mathrm{mmHg})$, median $\left(\mathrm{P}_{25}-\mathrm{P}_{75}\right)$ & $78(72-84)$ & $78(73-84)$ & $77(72-84)$ \\
\hline $\operatorname{MBP}(\mathrm{mmHg})$, median $\left(\mathrm{P}_{25}-\mathrm{P}_{75}\right)$ & 91 (85-99) & 91 (84-96) & $92(85-101)$ \\
\hline $\mathrm{HR}(\mathrm{bpm})$, median $\left(\mathrm{P}_{25}-\mathrm{P}_{75}\right)$ & $63(57-70)$ & $66(60-74)$ & $62(56-69)$ \\
\hline $\mathrm{SVI}\left(\mathrm{ml} / \mathrm{m}^{2}\right)$, median $\left(\mathrm{P}_{25}-\mathrm{P}_{75}\right)$ & $43(35-51)$ & $37(31-45)$ & $46(39-54)$ \\
\hline $\mathrm{Cl}\left(\mathrm{l} / \mathrm{min} / \mathrm{m}^{2}\right)$, median $\left(\mathrm{P}_{25}-\mathrm{P}_{75}\right)$ & $2.7(2.4-3.1)$ & $2.6(2.3-2.8)$ & $2.8(2.5-2.4)$ \\
\hline LCWI $\left(\mathrm{kg} \cdot \mathrm{m} / \mathrm{m}^{2}\right)$, median $\left(\mathrm{P}_{25}-\mathrm{P}_{75}\right)$ & $3.3(2.7-3.8)$ & $3.1(2.6-3.5)$ & $3.4(2.9-4.4)$ \\
\hline SVRI (dyne.s. $\left.\mathrm{cm}^{5} / \mathrm{m}^{2}\right)$, median $\left(\mathrm{P}_{25}-\mathrm{P}_{75}\right)$ & $2599(2212-3083)$ & $2797(2477-3185)$ & $2472(2142-2922)$ \\
\hline VI $(1 / 1000 / s)$, median $\left(P_{25}-P_{75}\right)$ & $39(31-48)$ & $36(29-44)$ & $40(31-49)$ \\
\hline
\end{tabular}

$A H T$ antihypertensive, $C I$ cardiac index, $C K D$ chronic kidney disease, COPD chronic obstructive pulmonary disease, $D B P$ diastolic blood pressure, $H R$ heart rate, $L C W I$ left cardiac work index, $L V D D$ left ventricle diastolic dysfunction, MBP mean blood pressure, OSA obstructive sleep apnoea, SBP systolic blood pressure, SVI stroke volume index, SVRI systemic vascular resistance index, VI Aorta velocity index 
Table 3 Distribution of the values of measurements obtained by ICG considered to be used to screen LVDD ( $n=157)$. Mann-Whitney test

\begin{tabular}{llll}
\hline & $\begin{array}{l}\text { All patients } \\
(n=157)\end{array}$ & $\begin{array}{l}\text { Without LVDD } \\
(n=55)\end{array}$ & $\begin{array}{l}\text { With LVDD } \\
(n=102)\end{array}$ \\
\hline PEP $(\mathrm{ms})$, median $\left(\mathrm{P}_{25}-\mathrm{P}_{75}\right)$ & 93 & 105 & 88 \\
& $(80-105)$ & $(96-120)$ & $(74-95)$ \\
LVET $(\mathrm{ms})$, median $\left(\mathrm{P}_{25}-\mathrm{P}_{75}\right)$ & 332 & 290 & 353 \\
& $(291-370)$ & $(262-320)$ & $(320-383)$ \\
STR, median $\left(\mathrm{P}_{25}-\mathrm{P}_{75}\right)$ & 0.28 & 0.36 & 0.26 \\
& $(0.21-0.33)$ & $(0.32-0.41)$ & $(0.22-0.28)$ \\
TFC $(1 / \mathrm{k} \Omega)$, median $\left(\mathrm{P}_{25}-\mathrm{P}_{75}\right)$ & 31.3 & 30.7 & 31.6 \\
& $(27.6-34.7)$ & $(27.4-34.0)$ & $(27.9-35.2)$ \\
D wave, $\mathrm{n}(\%)$ & 83 & 2 & 81 \\
& $(52.9)$ & $(1.9)$ & $(79.4)$ \\
\hline
\end{tabular}

ICG impedance cardiography, LVDD left ventricular diastolic dysfunction, LVET left ventricle ejection time, PEP pre-ejection period, STR systolic time ratio, TFC thoracic fluid content

LVDD screening: PEP $\leq 104 \mathrm{~ms}$, LVET $\geq 320 \mathrm{~ms}$; STR $\leq 0.31$. Table 4 presents the results of the LVDD diagnostic evaluation with the ICG variables PEP, LVET, STR and D wave.

The misclassification of LVDD using STR affected 6 cases, one false negative (FN) and five false positive (FP). The only FN case had STR $=0.32$, which is only slightly above the cut-off value 0.31 . No demographic, clinical and hemodynamic characteristics were found that differentiated the misclassified cases from the rest of the sample.

\section{Discussion}

In the IMPEDDANS study, the STR, with sensitivity of $99.0 \%$ and specificity of $90.9 \%$, outperformed the other analysed variables as screening test for LVDD. This index only misclassified 5 FP cases, which determine a 95.3\% PPV, and 1 FN case, which determines a $98.0 \% \mathrm{NPV}$.

In the IMPEDDANS study, PEP $\leq 104$ ms was identified as a good screening test for LVDD with sensitivity of $90.2 \%$ and PPV of $79.3 \%$. PEP extends from the onset
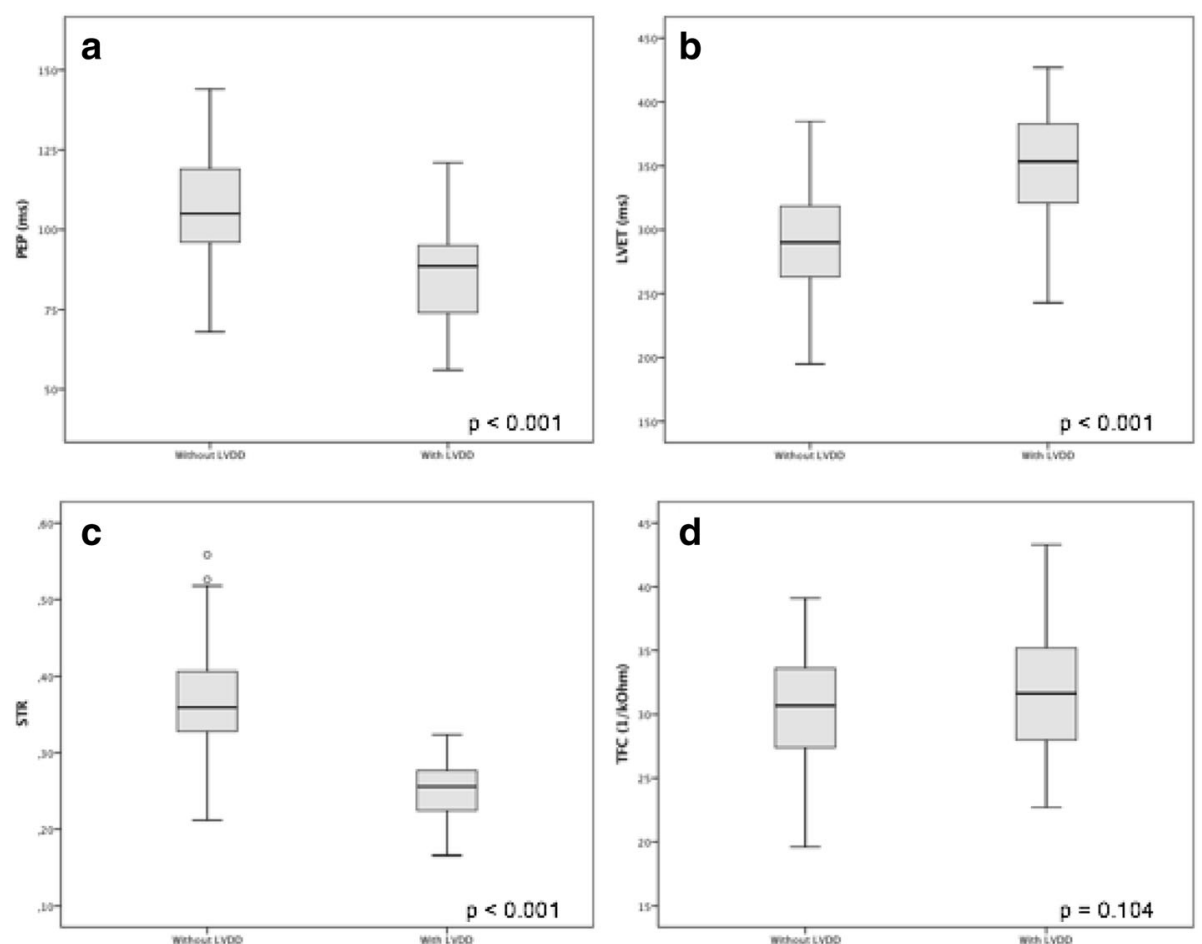

Fig. 3 Distribution of the values of (a) pre-ejection period (PEP), b left ventricle ejection time (LVET), c systolic time ratio (STR) and $\mathbf{d}$ thoracic fluid content (TFC), as assessed by ICG, according with the diagnosis of LVDD (left ventricular diastolic dysfunction) by echocardiography. Graphics represent the interquartile range $\left(\mathrm{P}_{25}-\mathrm{P}_{75}\right)$, median, limits and outliers. Comparison by Mann-Whitney test 


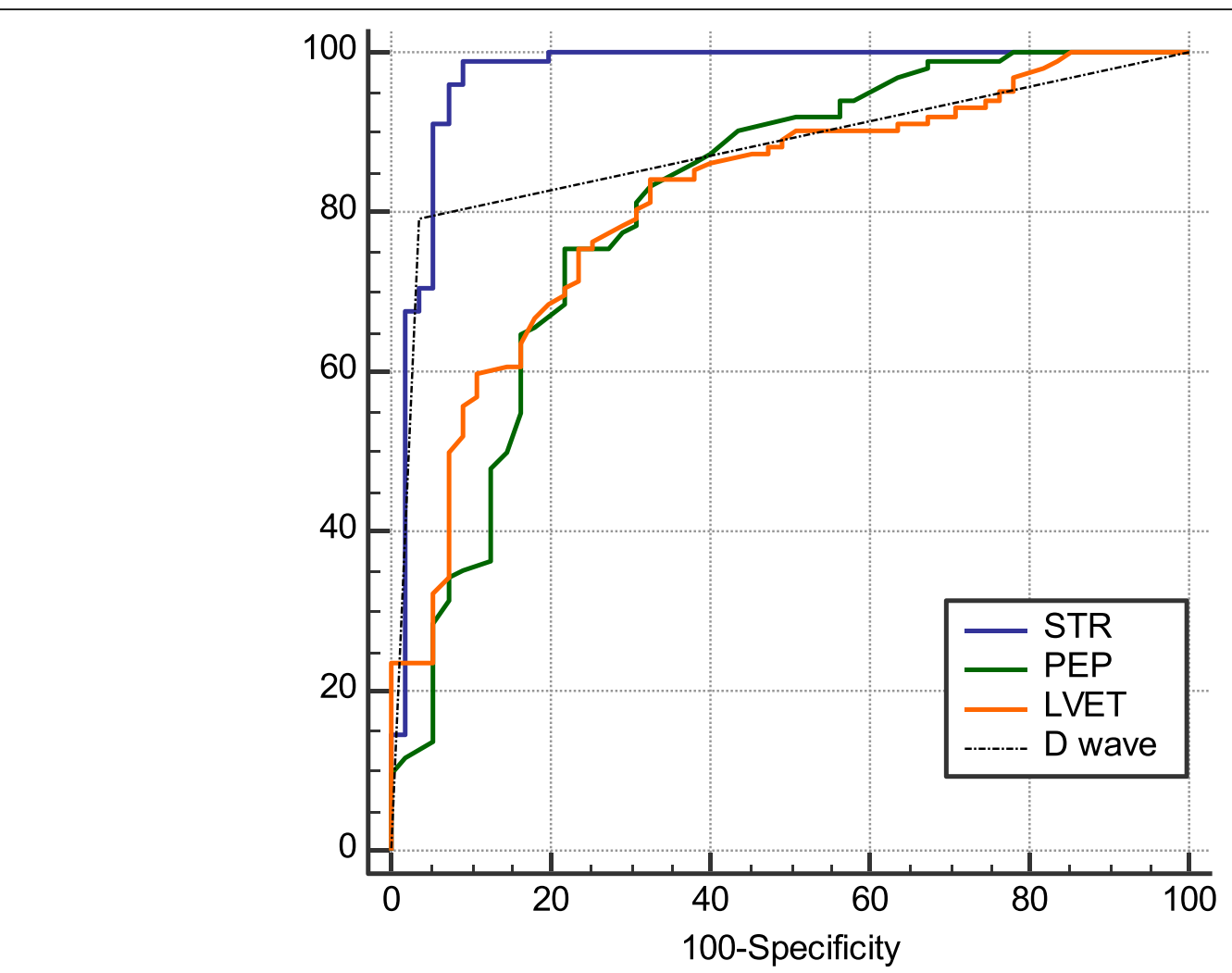

Fig. 4 Discriminative ability of PEP, LVET, STR and D wave to identify LVDD in hypertensive patients, as determined by the AUC and ROC curves. STR AUC $=0.97 ;$ PEP AUC $=0.81 ;$ LVET AUC $=0.82 ; \mathrm{D}$ Wave $A U C=0.88$. AUC, area under the curve; LVDD, left ventricular diastolic dysfunction; LVET, left ventricle ejection time; PEP, pre-ejection period; STR, systolic time ratio

of ventricular depolarization to the opening of the aortic valve. It is composed of two sub-intervals, known as the period of the electromechanical coupling and the period of elevation of pressure (or isovolumetric systole). The electromechanical coupling period undergoes few changes in acute interventions, but changes in the final diastolic pressure, aortic diastolic pressure and in the mean velocity of elevation of LV pressure (usually predominantly) in this period are the factors that determine the period of pressure rise and, consequently, PEP. Elevation of LV end-diastolic pressure (LVEDP), reduction of aortic diastolic pressure or gain in the rate of pressure increase in the pre-ejection period, lead to a time reduction. In mild LVDD, we expect a rise in LVEDP and a shortening of PEP, as we confirmed in this sample [16-18]. However, we must point out that LVEDP, aortic diastolic pressure or alterations in the rate of pressure increase can act simultaneously and we can have an unexpected PEP time. For example, in the established heart failure, the final diastolic pressure is increased, but the rate of ventricular pressure elevation in the pre-ejective period is so slow that it predominates

Table 4 Diagnostic performance of ICG-derived indexes for identification of LVDD, for the identified cut-off points ( $n=157$ )

\begin{tabular}{|c|c|c|c|c|c|c|c|c|}
\hline Index and cut-off & TP & FP & TN & $\mathrm{FN}$ & $\begin{array}{l}\text { Sensitivity \% } \\
(95 \% \mathrm{Cl})\end{array}$ & $\begin{array}{l}\text { Specificity \% } \\
(95 \% \text { Cl) }\end{array}$ & $\begin{array}{l}\text { PPV \% } \\
(95 \% \text { CI) }\end{array}$ & $\begin{array}{l}\text { NPV \% } \\
(95 \% \text { Cl) }\end{array}$ \\
\hline $\begin{array}{l}\text { PEP } \\
\leq 104 \mathrm{~ms}\end{array}$ & 92 & 24 & 31 & 10 & $\begin{array}{l}90.2 \\
(82.7-95.2)\end{array}$ & $\begin{array}{l}56.4 \\
(42.3-69.7)\end{array}$ & $\begin{array}{l}79.3 \\
(73.8-83.9)\end{array}$ & $\begin{array}{l}75.6 \\
(62.2-85.4)\end{array}$ \\
\hline $\begin{array}{l}\text { LVET } \\
\geq 290 \mathrm{~ms}\end{array}$ & 92 & 28 & 27 & 10 & $\begin{array}{l}90.2 \\
(82.7-95.2)\end{array}$ & $\begin{array}{l}49.1 \\
(35.4-62.9)\end{array}$ & $\begin{array}{l}76.6 \\
(71.6-81.1)\end{array}$ & $\begin{array}{l}72.9 \\
(58.6-83.8)\end{array}$ \\
\hline $\begin{array}{l}\text { STR } \\
\leq 0.31\end{array}$ & 101 & 5 & 50 & 1 & $\begin{array}{l}99.0 \\
(94.7-99.9)\end{array}$ & $\begin{array}{l}90.9 \\
(80.0-96.9)\end{array}$ & $\begin{array}{l}95.3 \\
(89.8-97.9)\end{array}$ & $\begin{array}{l}98.0 \\
(87.7-99.7)\end{array}$ \\
\hline D wave presence & 81 & 2 & 53 & 21 & $\begin{array}{l}79.4 \\
(70.3-86.8)\end{array}$ & $\begin{array}{l}96.4 \\
(87.5-99.6)\end{array}$ & $\begin{array}{l}97.6 \\
(91.2-99.4)\end{array}$ & $\begin{array}{l}71.6 \\
(63.2-78.8)\end{array}$ \\
\hline
\end{tabular}

FN false negative diagnostics, $F P$ false positive diagnostics, NPV negative predictive value, $L V D D$ left ventricular diastolic dysfunction, $L V E T$ left ventricle ejection time, PEP pre-ejection period, PPV positive predictive value, STR systolic time ratio, TN true negative diagnostics, TP true positive diagnostics 
and prolongs PEP. In this sample, it was not the case, because we excluded the patients with heart failure [16$18]$.

Increased LVET ( $\geq 320 \mathrm{~ms}$ ) was also a good LVDD screening tool with sensitivity $90.2 \%$, and PPV 76.6\%. Considering that active relaxation can be considered in the strictest sense as an early diastolic event, the time of onset of this process depends, at least in part, on systolic events such as the duration of contraction. In LVDD, increases in load during the contraction phase induce compensatory increases in duration of systole (LVET) and delayed onset of relaxation, which explain these results [27, 28].

The diastolic properties of the LV are largely determined by the size or volume of the LV, the thickness, physical properties of the ventricular wall and the relaxation process of the myocardium. Thus, a combination of increased myocardial mass and changes in the extracellular collagen network may cause or contribute to an increase in the passive elastic rigidity of the ventricle with a diastolic pressurevolume relation represented by a steep curve. Disorders of the active myocardial relaxation process, acting alone or in conjugation with abnormal passive ventricular properties, may also cause increased ventricular rigidity. As a result, there is a reduction in the compliance and distensibility of the ventricle, the filling dynamics are changed and the final diastolic pressure increases. Under these circumstances, as the disease progresses, an increase in central blood volume may produce a substantial increase in LV diastolic pressure and, consequently, cause some degree of pulmonary congestion, which can be evidenced by an increase in TFC $[13,29,30]$. In the IMPEDDANS study, however, we did not verify any relation between LVDD and TFC. We hypothesize that this is related with the important proportion of resistant hypertensive patients which are polymedicated ( $n=117,74.5 \%$ of the total sample; $48.4 \%$ of the patients with LVDD, $n=76$ ), most of them taking diuretics $(n=82,80.4 \%)$. On the other hand, pulmonary congestion is more common in an advanced phase of hypertensive disease, when patients start to evidence heart failure symptoms, which were not included (only patients with mild asymptomatic LVDD were included).

During early diastole, the occurrence of a prominent wave may indicate diastolic dysfunction. As such, the presence of a pronounced diastolic $\mathrm{O}$ wave ( $\mathrm{D}$ wave), in either upright or supine position, can be assumed as an evidence of diastolic dysfunction [2]. Thus, it was verified that the presence of a $D$ wave was statistically related with LVDD and that it had good performance screening LVDD, with $79.4 \%$ of sensitivity and $97.6 \%$ PPV.

Our observational study has some weak points: the two tests were performed within a time lapse of 8 days. In order to minimize this weakness, evaluations matching variations $>10 \%$ in $\mathrm{BP}$ or variations $>5 \%$ in $\mathrm{HR}$ were not considered. Although sample was recruited by convenience of researchers all patients had strict inclusion and exclusion criteria, were submitted to the same evaluation protocols and patients were recruited non-consecutively. Significant strengths are the exclusion of the elderly (due to the influence of age on the physiopathology of diastolic dysfunction), and the fact that examinations have been performed in a clinical environment controlled by experienced professionals under well-defined protocols.

Recommendations for the diagnosis of diastolic dysfunction were updated in 2016 (Fig. 5 presents the diagnostic approach proposed) [31]. However, there is no real consensus in the scientific community regarding its

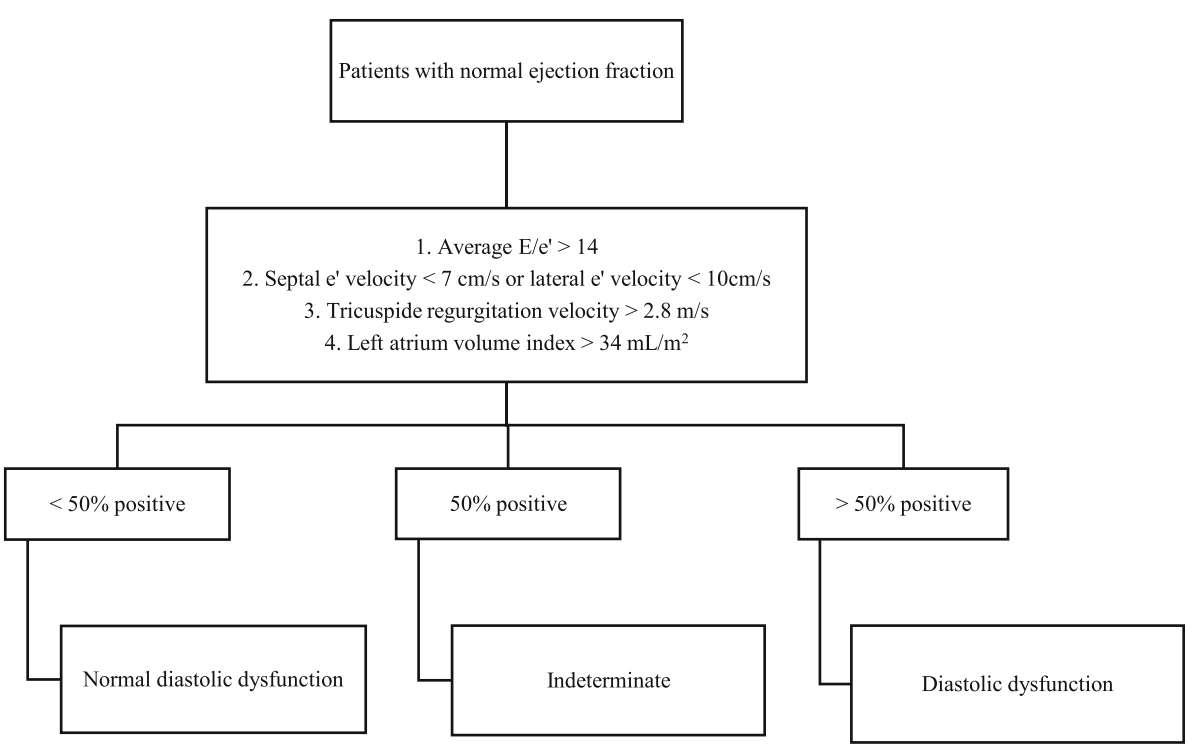

Fig. 5 Practical approach to diagnose diastolic dysfunction (adapted from Nagueh et al. [31]) 
applicability due to the fact that they have not yet been duly validated and just during this year was presented the first trial studying their applicability being difficult to conclude about their performance [32, 33]. We can, however, admit that the new recommendations create situations in which diastolic dysfunction may be underdiagnosed. In fact, the inclusion of the tricuspid regurgitation peak velocity as a criterion for the diagnosis and classification of diastolic dysfunction may lead to some interpretation problems because high values may be due to pulmonary hypertension and its increase is usually associated with elevation of pulmonary artery pressure due to increased filling pressures of the left ventricle, phenomena present in advanced stages of diastolic dysfunction [34-37]. Thus, we can only diagnose diastolic dysfunction in patients with established heart failure and patients with diastolic dysfunction at an early stage may go unnoticed, which goes against the spirit of this study, whose aim is to diagnose patients at an early stage, asymptomatic, without heart failure. In addition, the adoption of new recommendations would bring the limitation of not allow to compare our results with previous studies and perform other substudies with the acquired data. After analyzing these points and considering that these recommendations were published in the middle of the study period, we chose to not integrate them into our protocol and to keep the previous recommendations, already studied and validated.

Despite all the potential demonstrated by the ICG, we must emphasize the importance of performing routine echocardiography in hypertensive patients, indispensable to provide the recommended basic echocardiographic assessments [4]. In hypertensive patients ICG can be a valid, cost effective alternative for LVDD screening, it might also be used to monitor follow-up and define patients who would benefit from early transthoracic echocardiography.

\section{Conclusions}

ICG can accurately screen LVDD in hypertensive patients, using its derived parameters STR, PEP, LVET and D wave. STR alone showed the highest discriminative ability. Therefore, we recommend its use as a LVDD screening tool.

Future ICG studies applying the diagnostic test for LVDD will probably increase our understanding of the physiopathology/hemodynamics of HT and demonstrate that earlier detection and treatment of these hemodynamic features will favour patients' evolution and, perhaps, reduce morbidity and mortality.

\section{Abbreviations}

AHT: Antihypertensive; AMBP: 24 hours ambulatory blood pressure monitoring; Ar: Atrial reverse velocity; AUC: Area under the curve; BO: Blood pressure; BSA: Body surface area; Cl: Confidence interval; Cln: Cardiac index; CKD: Chronic kidney disease; CO: Cardiac output; COPD: Chronic obstructive pulmonary disease; CVP: Central venous pressure; DBP: Diastolic blood pressure; DT: Deceleration time; EKG: Electrocardiogram; FN: False negatives; FP: False positives; HR: Heart rate; HT: Hypertension; ICG: Impedance cardiography; IRVT: Isovolumic relaxation time; LCW: Left cardiac work; LCWI: Left cardiac work index; LV: Left ventricle; LVDD: Left ventricle diastolic dysfunction; LVEDP: Left ventricle end diastolic pressure; LVET: Left ventricle ejection time; MAP: Mean blood pressure; MRI: Magnetic resonance imaging; NPV: Negative predictive value; OSA: Obstructive sleep apnea;

PAOP: Pulmonary artery occlusion pressure; PEP: Pre-ejection period; PPV: Positive predictive value; ROC: Receiver-operating characteristic; SBP: Systolic blood pressure; STR: Systolic time ratio; SV: Stroke volume; SVI: Stroke volume index; TFC: Thoracic fluid content; TFI: Thoracic fluid index; TN: True negatives; TP: True positives; VEPT: Volume of electrically participating tissue; VI: Aorta velocity index; VSR: Vascular systemic resistence; VSRI: Vascular systemic resistance index

\section{Acknowledgments}

We would like to thank Ana Rita Víctor, António Sousa Guerreiro, José Rola, Luís Dias, Rui Ferreira, who contributed with their knowledge, expertise to the protocol design and allowed IMPEDDANS study to be successfully completed in the departments they lead. We also would like to thank the cardiopneumology technician Paula Ribeiro for her effort and dedication performing ICG exams and Pedro Rio and Júlio Calaça for their performance and availability in the realization and revision of echocardiograms, respectively.

\section{Funding}

This study has no funding.

\section{Availability of data and materials}

The data that support the findings of this study are available from Centro Hospitalar Lisboa Central - EPE but restrictions apply to the availability of these data, which were used under license for the current study, and so are not publicly available. Data are however available from the authors upon reasonable request and with permission of the patients and Centro Hospitalar Lisboa Central - EPE administration.

\section{Authors' contributions}

All authors contributed to the acquisition, analysis and interpretation of data. All authors drafted and revised the manuscript. They approve and agree to be accountable for all aspects of work.

Ethics approval and consent to participate

The study protocol was approved by the hospital's Ethics Committee (approval number 166/2014). Informed consent was obtained from each patient.

Consent for publication

Patients gave consent to publication.

Competing interests

The authors declare that they have no competing interests.

\section{Publisher's Note}

Springer Nature remains neutral with regard to jurisdictional claims in published maps and institutional affiliations.

\footnotetext{
Author details

'Unidade Funcional Medicina 1.2, Hospital de São José, Centro Hospitalar Lisboa Central-EPE, Rua José António Serrano, 1150-199 Lisboa, Portugal. ${ }^{2}$ NOVA Medical School, Universidade NOVA de Lisboa, Lisboa, Portugal. ${ }^{3}$ Núcleo de Investigação Arterial, Unidade Funcional Medicina 4, Hospital Santa Marta, Centro Hospitalar Lisboa Central-EPE, Lisboa, Portugal.

${ }^{4}$ Laboratório de Ecocardiografia, Serviço de Cardiologia, Hospital de Santa Marta, Centro Hospitalar de Lisboa Central-EPE, Lisboa, Portugal. ${ }^{5}$ Unidade de Cardiologia, Hospital Pulido Valente, Centro Hospitalar Lisboa Norte-EPE, Lisboa, Portugal. ${ }^{6}$ Gabinete de Análise Epidemiológica e Estatística, Centro de Investigação, Centro Hospitalar Lisboa Central-EPE, Lisboa, Portugal.
} 
Received: 9 August 2017 Accepted: 30 November 2017

Published online: 27 December 2017

\section{References}

1. Mills KT, Bundy JD, Kelly TN, Reed JE, Kearney PM, Reynolds K, Chen J, He J. Global disparities of hypertension prevalence and control: a systematic analysis of population-based studies from 90 countries. Circulation. 2016; 134(6):441-50.

2. Nazario Leao R, Marques da Silva P. Diastolic dysfunction in hypertension. Hipertens Riesgo Vasc. 2017;34(3):128-39.

3. Messerli FH, Rimoldi SF, Bangalore S. The transition from hypertension to heart failure: contemporary update. JACC Heart Fail. 2017;5:543.

4. Mancia G, Fagard R, Narkiewicz K, Redon J, Zanchetti A, Bohm M, Christiaens T, Cifkova R, De Backer G, Dominiczak A, et al. 2013 ESH/ESC guidelines for the management of arterial hypertension: the task force for the management of arterial hypertension of the European Society of Hypertension (ESH) and of the European Society of Cardiology (ESC). Eur Heart J. 2013;34(28):2159-219.

5. Bour J, Kellett J. Impedance cardiography: a rapid and cost-effective screening tool for cardiac disease. Eur J Intern Med. 2008;19(6):399-405.

6. Ventura HO, Taler SJ, Strobeck JE. Hypertension as a hemodynamic disease: the role of impedance cardiography in diagnostic, prognostic, and therapeutic decision making. Am J Hypertens. 2005;18(2 Pt 2):26S-43S.

7. Patterson RP. Fundamentals of impedance cardiography. IEEE Eng Med Biol Mag. 1989;8(1):35-8.

8. Cybulski G, Strasz A, Niewiadomski W, Gasiorowska A. Impedance cardiography: recent advancements. Cardiol J. 2012;19(5):550-6.

9. Cybulski G. Ambulatory impedance cardiography: new possibilities. J Appl Physiol (1985). 2000;88(4):1509-10.

10. Harvey $S$, Harrison DA, Singer $M$, Ashcroft J, Jones CM, Elbourne D, Brampton W, Williams D, Young D, Rowan K, et al. Assessment of the clinical effectiveness of pulmonary artery catheters in management of patients in intensive care (PAC-Man): a randomised controlled trial. Lancet. 2005;366(9484):472-7.

11. Richard C, Warszawski J, Anguel N, Deye N, Combes A, Barnoud D, Boulain T, Lefort $Y$, Fartoukh M, Baud F, et al. Early use of the pulmonary artery catheter and outcomes in patients with shock and acute respiratory distress syndrome: a randomized controlled trial. JAMA. 2003;290(20):2713-20.

12. Tang $\mathbf{W H}$, Tong $\mathbf{W}$. Measuring impedance in congestive heart failure: current options and clinical applications. Am Heart J. 2009;157(3):402-11.

13. Zile MR, Brutsaert DL. New concepts in diastolic dysfunction and diastolic heart failure: part I: diagnosis, prognosis, and measurements of diastolic function. Circulation. 2002;105(11):1387-93.

14. DeMarzo AP, Calvin JE. A new approach for low-cost noninvasive detection of asymptomatic heart disease at rest. Prev Cardiol. 2007;10(1):9-14.

15. DeMarzo AP. Using impedance cardiography with postural change to stratify patients with hypertension. Ther Adv Cardiovasc Dis. 2011;5(3):139-48.

16. Talley RC, Meyer JF, McNay JL. Evaluation of the pre-ejection period as an estimate of myocardial contractility in dogs. Am J Cardiol. 1971;27(4):384-91.

17. Martin CE, Shaver JA, Thompson ME, Reddy PS, Leonard JJ. Direct correlation of external systolic time intervals with internal indices of left ventricular function in man. Circulation. 1971:44(3):419-31.

18. Sant Anna JRM. Valorização do período de pré-ejeção na dinâmica cardiovascular. Rev Bras Marcapasso e Arritmia. 1971;7(1):5-12.

19. Weber T, Auer J, O'Rourke MF, Punzengruber C, Kvas E, Eber B. Prolonged mechanical systole and increased arterial wave reflections in diastolic dysfunction. Heart. 2006;92(11):1616-22

20. Malfatto G, Branzi G, Giglio A, Villani A, Facchini C, Ciambellotti F, Facchini M, Parati G. Transthoracic bioimpedance and brain natriuretic peptide levels accurately indicate additional diastolic dysfunction in patients with chronic advanced systolic heart failure. Eur J Heart Fail. 2010;12(9):928-35.

21. CM Y, Wang L, Chau E, Chan RH, Kong SL, Tang MO, Christensen J, Stadler RW, Lau CP. Intrathoracic impedance monitoring in patients with heart failure: correlation with fluid status and feasibility of early warning preceding hospitalization. Circulation. 2005;112(6):841-8.

22. New York Heart Association. Criteria C: nomenclature and criteria for diagnosis of diseases of the heart and great vessels. 7th ed. Boston: Little, Brown and Company; 1973.

23. Kane GC, Karon BL, Mahoney DW, Redfield MM, Roger VL, Burnett JC Jr, Jacobsen SJ, Rodeheffer RJ. Progression of left ventricular diastolic dysfunction and risk of heart failure. JAMA. 2011;306(8):856-63.
24. Owan TE, Hodge DO, Herges RM, Jacobsen SJ, Roger VL, Redfield MM Trends in prevalence and outcome of heart failure with preserved ejection fraction. N Engl J Med. 2006;355(3):251-9.

25. Nagueh SF, Appleton CP, Gillebert TC, Marino PN, JK O, Smiseth OA Waggoner AD, Flachskampf FA, Pellikka PA, Evangelisa A. Recommendations for the evaluation of left ventricular diastolic function by echocardiography. Eur J Echocardiogr. 2009;10(2):165-93.

26. DeLong ER, DeLong DM, Clarke-Pearson DL. Comparing the areas under two or more correlated receiver operating characteristic curves: a nonparametric approach. Biometrics. 1988;44(3):837-45.

27. Brutsaert DL, Sys SU. Diastolic dysfunction in heart failure. J Card Fail. 1997; 3(3):225-42

28. Munagala VK, Hart CY, Burnett JC Jr, Meyer DM, Redfield MM. Ventricular structure and function in aged dogs with renal hypertension: a model of experimental diastolic heart failure. Circulation. 2005;111(9):1128-35.

29. Gaasch WH, Zile MR. Left ventricular diastolic dysfunction and diastolic heart failure. Annu Rev Med. 2004:55:373-94.

30. Nishimura RA, Tajik AJ. Evaluation of diastolic filling of left ventricle in health and disease: Doppler echocardiography is the clinician's Rosetta Stone. J Am Coll Cardiol. 1997:30(1):8-18.

31. Nagueh SF, Smiseth OA, Appleton CP, Byrd BF 3rd, Dokainish H, Edvardsen T, Flachskampf FA, Gillebert TC, Klein AL, Lancellotti $P$, et al. Recommendations for the evaluation of left ventricular diastolic function by echocardiography: an update from the American Society of Echocardiography and the European Association of Cardiovascular Imaging. Eur Heart J Cardiovasc Imaging. 2016:17(12):1321-60.

32. Mitter SS, Shah SJ, Thomas JD. A test in context: E/A and E/e' to assess diastolic dysfunction and LV filling pressure. J Am Coll Cardiol. 2017;69(11):1451-64.

33. Andersen OS, Smiseth OA, Dokainish $H$, Abudiab MM, Schutt RC, Kumar A, Sato K, Harb S, Gude E, Remme EW, et al. Estimating left ventricular filling pressure by echocardiography. J Am Coll Cardiol. 2017;69(15):1937-48.

34. Enriquez-Sarano M, Rossi A, Seward JB, Bailey KR, Tajik AJ. Determinants of pulmonary hypertension in left ventricular dysfunction. J Am Coll Cardiol. 1997;29(1):153-9.

35. Galie N, Humbert M, Vachiery JL, Gibbs S, Lang I, Torbicki A, Simonneau G, Peacock A, Vonk Noordegraaf A, Beghetti M, et al. 2015 ESC/ERS guidelines for the diagnosis and treatment of pulmonary hypertension: the joint task force for the diagnosis and treatment of pulmonary hypertension of the European Society of Cardiology (ESC) and the European Respiratory Society (ERS): Endorsed by: Association for European Paediatric and Congenital Cardiology (AEPC), International Society for Heart and Lung Transplantation (ISHLT). Eur Heart J. 2016:37(1):67-119.

36. Moller JE, Hillis GS, JK O, Pellikka PA. Prognostic importance of secondary pulmonary hypertension after acute myocardial infarction. Am J Cardiol. 2005;96(2):199-203.

37. Neuman Y, Kotliroff A, Bental T, Siegel RJ, David D, Lishner M. Pulmonary artery pressure and diastolic dysfunction in normal left ventricular systolic function. Int J Cardiol. 2008;127(2):174-8.

\section{Submit your next manuscript to BioMed Central and we will help you at every step:}

- We accept pre-submission inquiries

- Our selector tool helps you to find the most relevant journal

- We provide round the clock customer support

- Convenient online submission

- Thorough peer review

- Inclusion in PubMed and all major indexing services

- Maximum visibility for your research

Submit your manuscript at www.biomedcentral.com/submit
) Biomed Central 